Note

\title{
Inhibitory Activities of Proanthocyanidins from Persimmon against Oxidative Stress and Digestive Enzymes Related to Diabetes
}

\author{
Young A LEE ${ }^{1}$, Eun Ju CHO ${ }^{2}$, Takashi TANAKA ${ }^{3}$ and Takako YoKOZAWA ${ }^{1, *}$ \\ ${ }^{1}$ Institute of Natural Medicine, University of Toyama, 2630 Sugitani, Toyama 930-0194, Japan \\ ${ }^{2}$ Department of Food Science and Nutrition, Pusan National University, 30 Jangjeon-dong, \\ Geumjeong-gu, Busan 609-735, Korea \\ ${ }^{3}$ Graduate School of Biomedical Sciences, Nagasaki University, \\ 1-14 Bunkyo-cho, Nagasaki 852-8521, Japan \\ (Received October 10, 2006)
}

\begin{abstract}
Summary The present study was carried out to evaluate the promising potential of polymers and oligomers from proanthocyanidins of persimmon peel as antioxidants and therapeutic agents for diabetes. Both polymers and oligomers showed the scavenging effect of 2,2diphenyl-1-picrylhydrazyl, with $\mathrm{IC}_{50}$ values of 4.35 and $2.41 \mu \mathrm{g} / \mathrm{mL}$, respectively, and they also showed a protective activity against protein oxidation induced by $2,2^{\prime}$-azobis (2-amidinopropane) dihydrochloride. In particular, oligomers exerted a stronger activity against free radicals than polymers. In addition, to investigate their protective potential against diabetesrelated pathological conditions, their inhibitory activities on digestive enzymes and advanced glycation endproduct (AGE) formation were evaluated. Polymers showed a strong inhibitory activity against $\alpha$-amylase, while oligomers had a relatively weak effect. This suggests that the inhibition of $\alpha$-amylase activity would probably depend on the degree of polymerization. On the other hand, against $\alpha$-glucosidase activity and AGE formation, oligomers exerted a stronger protective effect than polymers. The present study suggests that polymers and oligomers from proanthocyanidins of persimmon peel could play a role as antidiabetic agents with antioxidative effects. Moreover, oligomers rather than polymers from proanthocyanidins of persimmon peel may be expected to be a more promising antioxidative and antidiabetic agent in relation to utilization in biological systems.
\end{abstract}

Key Words proanthocyanidins, oligomers, diabetes, antioxidant, persimmon

Oxidative stress, caused by the imbalance of reactive oxygen species (ROS) and antioxidative defense systems, is considered as a major etiological and/or pathogenic agent of most degenerative diseases such as cancer, Alzheimer's, diabetes, and aging (1-4). Under conditions of diabetes, oxidative stress increases due to several factors: enhancement of glucose autoxidation, stimulation of the polyol pathway, production of advanced glycation endproduct (AGE), reduction of antioxidant defenses by the depletion of antioxidants such as glutathione and vitamin $\mathrm{E}$, and decrease in the activity of antioxidative enzyme (5-7). Therefore, antioxidants that can scavenge ROS and/or enhance antioxidant defense have received much attention in an attempt to reduce the risk of diabetes-associated pathological damage as well as diabetes itself.

Proanthocyanidins, which belong to a class of polyphenols, are widely distributed in plants, fruits, legume seeds, wine, and tea. Persimmon is one of the proanthocyanidin-rich foods, with the peel showing higher contents than the pulp $(8,9)$. Various epidemiological data have suggested that proanthocyanidins pre-

*To whom correspondence should be addressed.
E-mail: yokozawa@inm.u-toyama.ac.jp vent cancer and cardiovascular diseases in humans (10). Ariga (11) suggested the utilization of proanthocyanidins related with an antioxidative function and preventive action on diseases. Proanthocyanidins are absorbed through the gut barrier and their absorption depends on the degree of polymerization. It is considered that their polymers would play the functional roles of proanthocyanidins in biological systems. However, the functional properties derived from their polymerization are poorly understood. Therefore, in the present study we extracted proanthocyanidins from persimmon peel, and disintegrated polymers and oligomers from these proanthocyanidins to investigate their potential as antioxidants and therapeutic agents against diabetes.

\section{Materials and Methods}

Fractionation of polymers and oligomers from proanthocyanidins of persimmon peel. A mixture of freshly crushed persimmon peel (green and $5-7 \mathrm{~cm}$ in diameter, $3 \mathrm{~kg}$ ) and dried green tea leaves $(450 \mathrm{~g})$ in water containing citric acid $(240 \mathrm{~g})$ was boiled for $3 \mathrm{~h}$. At this stage, nucleophilic substitution at the C-4 positions of polymeric proanthocyanidins with monomeric tea catechins occurred, and consequently, the polymeric molecules were converted into oligomers. After cooling, 
insoluble materials were removed by filtration, and the filtrate was directly applied to a Sepabeads SP 825 column (10 cm i.d. $\times 45 \mathrm{~cm}$, Mitsubishi Chemical Co.). Elution with water $(4 \mathrm{~L})$ washed out non-phenolic compounds consisting of citric acid, sugars, minerals, amino acids, etc. Further elution with water containing increasing amounts of ethanol (20-80\% ethanol, 20\% stepwise elution, each $2 \mathrm{~L}$ ) yielded a mixture of oligomeric proanthocyanidins and tea catechins (72.2 g). The mixture was subsequently subjected to Sephadex LH-20 column chromatography with ethanol. The monomeric tea catechins were eluted out with ethanol, and further elution with $50 \%$ aqueous acetone yielded oligomers $(51.5 \mathrm{~g})$. The degree of oligomeric polymerization was estimated as 3.3 by quantitative HPLC analysis of thiol degradation products (12), while the unit ratios of epigallocatechin, epicatechin, epigallocatechin3-O-gallate, and epicatechin-3-O-gallate in oligomers were determined as $47,15,31$, and $6 \%$, respectively. The preparation of persimmon polymeric proanthocyanidins was as follows: an aqueous acetone extract of fresh persimmon peel $(500 \mathrm{~g})$ was concentrated, and the resulting insoluble precipitates were removed by filtration. The filtrate was subjected to MCI-gel CHP 20P (Mitsubishi Chemical. Co.) column chromatography with water containing methanol (0-80\%, 20\% stepwise elution) to give polymers $(6.93 \mathrm{~g})$.

Reagents. 2,2-Diphenyl-1-picrylhydrazyl (DPPH), 2,2'azobis (2-amidinopropane) dihydrochloride (AAPH) and glutathione were purchased from Wako Pure Chemical Industries, Ltd. (Osaka, Japan), and allophycocyanin was obtained from Funakoshi Co., Ltd. (Tokyo, Japan). $\alpha$-Amylase (from Bacillus licheniformis), $\alpha$-glucosidase (from Saccharomyces cerevisiae) type I, 3,5-dinitrosalicylic acid, sodium potassium tartrate (Rochelle salt), and $\rho$-nitrophenyl- $\alpha$-D-glucopyranoside were purchased from Sigma Chemical Co. (St. Louis, MO, USA).

DPPH radical scavenging activity. One hundred microliters of $50 \%$ EtOH solution of the sample (control: 100 $\mu \mathrm{L}$ of $50 \% \mathrm{EtOH}$ ) was added to microwells followed by $100 \mu \mathrm{L}$ of $60 \mu \mathrm{M} \mathrm{DPPH}$ in EtOH, according to the method of Hatano et al. (13). After being mixed gently and left to stand for $30 \mathrm{~min}$ at room temperature, the DPPH radical level was measured with a Microplate Reader (GENios, TECAN Austria GmbH). The antioxidant activity of each sample was expressed as the $\mathrm{IC}_{50}$ value (concentration in $\mu \mathrm{g} / \mathrm{mL}$ to scavenge $\mathrm{DPPH}$ by $50 \%$ ) calculated from the log-dose inhibition curve. LAscorbic acid was used as a positive control.

AAPH-induced protein oxidation. According to the methods of Courderot-Masuyer et al. (14), the reaction mixture containing $37.5 \mathrm{nM}$ allophycocyanin, $3 \mathrm{mM}$ AAPH, and aqueous solution of test sample in $75 \mathrm{~mm}$ phosphate buffer ( $\mathrm{pH} 7.0$ ) was incubated at $37^{\circ} \mathrm{C}$. The fluorescence obtained just before the addition of the radical generator $\mathrm{AAPH}$ was used as the $100 \%$ value for that sample. Loss of fluorescence was measured every $5 \mathrm{~min}$ at an emission wavelength of $635 \mathrm{~nm}$ and an excitation wavelength of $590 \mathrm{~nm}$ using a Microplate reader (GENios, TECAN Austria $\mathrm{GmbH}$ ).
$\alpha$-Amylase inhibitory activity. A reaction mixture containing $1 \%$ starch solution and an aqueous solution of the test sample in $20 \mathrm{mM}$ phosphate buffer ( $\mathrm{pH}$ 6.7) was equilibrated to $20^{\circ} \mathrm{C}$, and then this mixture was incubated for $3 \mathrm{~min}$ at $20^{\circ} \mathrm{C}$ with $1 \mathrm{U}$ enzyme solution. After incubation, a reagent solution containing 3,5dinitrosalicylic acid and Rochelle salt dissolved in $2 \mathrm{M}$ $\mathrm{NaOH}$ was added, and then boiled for $15 \mathrm{~min}$. The absorbance at $540 \mathrm{~nm}$ was read for estimation of enzymatic activity and inhibitory activity was expressed as the decrease in absorbance compared with the reaction mixture containing buffer solution without the test sample (15).

$\alpha$-Glucosidase inhibitory activity. The bioassay method was adopted and modified from Sigma-Aldrich (www. sigmaaldrich.com) and Lee and Lee (16). A reaction mixture containing $0.7 \mathrm{U}$ enzyme solution, $3 \mathrm{~mm}$ reduced glutathione solution, and an aqueous solution of the test sample in $67 \mathrm{~mm}$ phosphate buffer ( $\mathrm{pH}$ 6.8) was equilibrated to $37^{\circ} \mathrm{C}$, and then $10 \mathrm{mM} \rho$-nitrophenyl- $\alpha$-D-glucopyranoside as a substrate was added to initiate the enzyme reaction. After incubation for exactly $20 \mathrm{~min}$ at $37^{\circ} \mathrm{C}$, this reaction was terminated by the addition of $100 \mathrm{mM} \mathrm{Na}_{2} \mathrm{CO}_{3}$. The absorbance at 400 $\mathrm{nm}$ was read for enzymatic activity and inhibitory activity was expressed as a decrease in absorbance compared with the reaction mixture containing buffer solution without the test sample.

Determination of AGE formation. According to the method of Vinson and Howard (17), test samples were added to a reaction mixture comprised of bovine serum albumin $(10 \mathrm{mg} / \mathrm{mL})$ in $50 \mathrm{mM}$ phosphate buffer $(\mathrm{pH}$ 7.2 ) with $0.02 \%$ sodium azide to prevent bacterial growth, $25 \mathrm{~mm}$ glucose, and $25 \mathrm{~mm}$ fructose and then mixed. After incubation at $37^{\circ} \mathrm{C}$ for $2 \mathrm{wk}$, the fluorescent reaction products were assayed using a Microplate reader (GENios, TECAN Austria $\mathrm{GmbH}$ ) with excitation and emission wavelengths set at $360 \mathrm{~nm}$ and $465 \mathrm{~nm}$, respectively. All incubations were conducted in quadruplicate. Aminoguanidine was used as a positive control.

Statistical analysis. The results are presented as the mean \pm SE. Differences among groups were analyzed by Student's $t$-test and those at $p<0.05$ were considered significant.

\section{Results}

\section{DPPH radical scavenging activity}

Table 1 shows the DPPH radical scavenging activity of polymers and oligomers from proanthocyanidins of persimmon peel. Polymers and oligomers scavenged DPPH radical by $50 \%$ at concentrations of 4.35 and $2.41 \mu \mathrm{g} / \mathrm{mL}$, respectively; therefore, the oligomers exerted a stronger inhibitory activity than the polymers.

\section{AAPH-induced protein oxidation}

The protective effect of polymers and oligomers against protein oxidation induced by AAPH is represented in Fig. 1. At a concentration of $0.1 \mu \mathrm{g} / \mathrm{mL}$, polymers and oligomers showed a weak protective effect against protein damage. However, via treatment with 

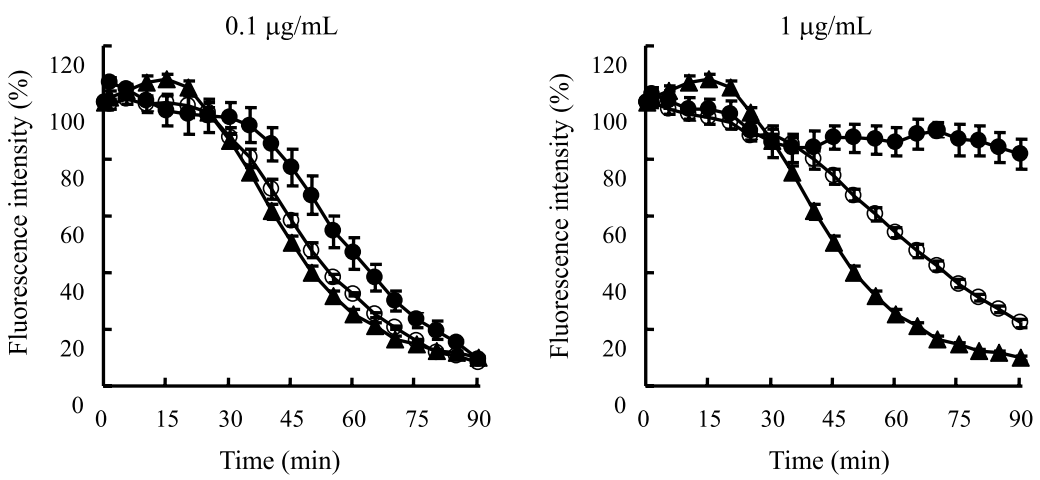

Fig. 1. Effect of proanthocyanidins from persimmon peel on free radical-mediated protein damage. $\mathbf{\Lambda}$ : control, $\bigcirc$ : polymers,

: oligomers.

Table 1. DPPH radical scavenging activity of proanthocyanidins of persimmon peel.

\begin{tabular}{lc}
\hline Material & $\mathrm{IC}_{50}(\mu \mathrm{g} / \mathrm{mL})$ \\
\hline Polymers & 4.35 \\
Oligomers & 2.41 \\
\hline Ascorbic acid & 0.97 \\
\hline
\end{tabular}

Table 2. Inhibitory activity of proanthocyanidins of persimmon peel against $\alpha$-amylase and $\alpha$-glucosidase.

\begin{tabular}{crrc}
\hline Enzyme & $\begin{array}{c}\text { Concentration } \\
(\mu \mathrm{g} / \mathrm{mL})\end{array}$ & Polymers & Oligomers \\
\hline$\alpha$-Amylase & 5 & $3.9 \pm 1.1$ & - \\
& 25 & $17.4 \pm 1.0$ & - \\
& 50 & $35.9 \pm 1.3$ & - \\
\hline$\alpha$-Glucosidase & 100 & $53.9 \pm 1.2$ & $4.6 \pm 4.0^{*}$ \\
& 5 & - & $53.6 \pm 2.8$ \\
& 50 & $29.9 \pm 4.1$ & $90.4 \pm 0.4^{*}$ \\
& 100 & $74.0 \pm 1.0$ & $96.2 \pm 0.3^{*}$ \\
& $57.4 \pm 0.1^{*}$ \\
\hline
\end{tabular}

${ }^{*} p<0.001$ vs. polymers.

$1 \mu \mathrm{g} / \mathrm{mL}$ of oligomers, the fluorescence after exposure to AAPH for $90 \mathrm{~min}$ was $81.7 \%$ compared with the control value of $9.8 \%$. On the other hand, polymers exerted a relatively weaker inhibitory activity than oligomers by showing a value of $22.1 \%$ at the same concentration.

Activities of $\alpha$-amylase and $\alpha$-glucosidase

Table 2 shows the inhibitory activity of polymers and oligomers against $\alpha$-amylase and $\alpha$-glucosidase. Polymers exerted an inhibitory activity against $\alpha$-amylase in a dose-dependent manner, while oligomers showed a weak effect. At a concentration of $100 \mu \mathrm{g} / \mathrm{mL}$, polymers and oligomers showed inhibitory activities of 53.9 and $4.6 \%$, respectively. Against $\alpha$-glucosidase, polymers and oligomers exerted inhibitory activities in a concentration-dependent manner. In particular, oligomers showed a strong inhibitory activity of $53.6 \%$ even at a low concentration of $5 \mu \mathrm{g} / \mathrm{mL}$, but polymers didn't

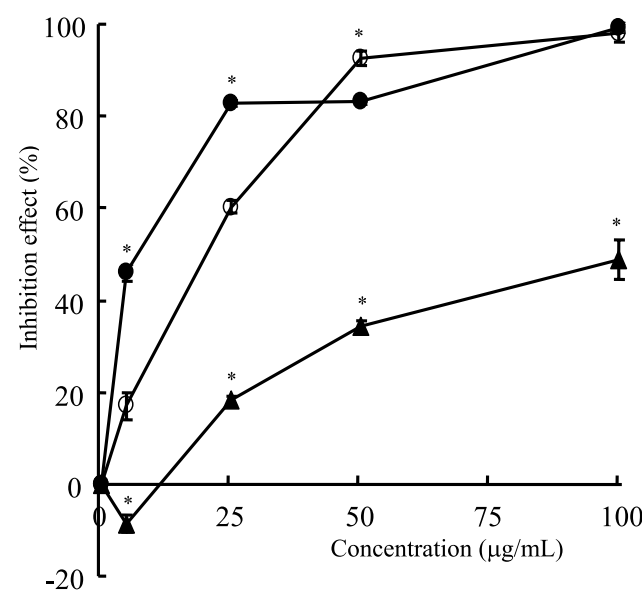

Fig. 2. Effect of proanthocyanidins from persimmon peel on AGE. $\bigcirc$ : polymers, $\bullet$ : oligomers, $\mathbf{\Delta}$ : aminoguanidine. ${ }^{*} p<0.001$ vs. polymers.

show such activity. Moreover, oligomers exerted an inhibitory activity over $90 \%$ at a higher concentration of $25 \mu \mathrm{g} / \mathrm{mL}$. Although polymers showed a relatively low inhibitory activity compared with oligomers, they also exerted inhibitory activities of 53.3 and $74.0 \%$ at concentrations of 50 and $100 \mu \mathrm{g} / \mathrm{mL}$, respectively. AGE formation

Figure 2 represents the effect of polymers and oligomers on AGE formation. They inhibited AGE formation dose-dependently; in particular, they showed a stronger effect than aminoguanidine. Oligomers showed a stronger inhibitory effect on AGE formation than polymers at a concentration lower than $25 \mu \mathrm{g} / \mathrm{mL}$, while both polymers and oligomers showed a higher than 95\% inhibitory effect on AGE.

\section{Discussion}

A large number of synthetic and natural antioxidants, which are potent scavengers of free radicals and promote the defense system, have been demonstrated to induce beneficial effects on human health and disease prevention $(18,19)$. In particular, proanthocyanidins are the most abundant polyphenolic compounds in plants and are common constituents of many foods and beverages. Several reports demonstrated that proanthocyanidins have been shown to be more effective antiox- 
idants than vitamins $\mathrm{E}$ and $\mathrm{C}$ on a molar basis $(8,19)$. Moreover, the number of their phenolic functional groups is at the origin of three essential properties, including the formation of complexes with proteins, formation of chelators with metal ions, and reducing capacity. The functional properties play a protective role against cancer and cardiovascular disease (10).

Proanthocyanidins differ from all other natural polyphenols by their polymeric nature (20). They are made of flavan-3-ol units and their average degree of polymerization generally varies between 3 and 11 . The polymerization degree was found to vary with the species, tissues or methods of extraction. The proanthocyanidins of persimmon peel are oligomers or polymers of flavan-3-ols characterized by a single interflavan bond linkage usually between $\mathrm{C}_{4}$ of the "upper" extension units and $\mathrm{C}_{8}$ or $\mathrm{C}_{6}$ of the "lower" or "starter" unit (21). Furthermore, structure of the proanthocyanidins was characterized as (-)-epicatechin- $(4 \beta-8)-(-)$-epigallocatechin-3-O-gallate, (-)-epigallocatechin- $(4 \beta-8)-(-)$ epigallocatechin-3-O-gallate and $(-)$-epigallocatechin3-O-gallate-(4 $\beta$-8)-(-)-epigallocatechin-3-O-gallate. We investigated the ratios of oligomer from persimmon peel by thiol degradation analysis (12). In this result, epicatechin gallate, epicatechin, epigallocatechin gallate and epicatechin gallate in oligomer were determined as 47 , 15,31 and $6 \%$, respectively. In the case of oligomers of proanthocyanidins from persimmon peels used in the present study, the polymerization degree was 3.3 and the higher degree was classified as polymers.

Absorption of proanthocyanidins through gut barrier depends on their degree of polymerization. Under in vitro experiments, only dimers and trimers, but not polymers with an average polymerization degree of 7 , were absorbed through an intestinal epithelium cell monolayer $(20,22,23)$. Low molecular proanthocyanidins are known as sustained release antioxidants; on the contrary, high molecular proanthocyanidins can exert their antioxidant activity in the digestive tract and protect lipids, proteins and carbohydrates from oxidative damage during digestion and spare soluble antioxidants (18). Accordingly, differences in their antioxidative activity and therapeutic potential due to their structural nature in relation to their utilization in biological systems have to be elucidated. In the present study, we analyzed the antioxidative and inhibitory activities against digestive enzymes and AGE formation with a comparison of the activities of polymers and oligomers.

As shown in the results of the DPPH radical scavenging effect, oligomers showed a stronger scavenging effect than polymers. It is well accepted that the DPPH radical scavenging by antioxidants is due to their hydrogen-donating activity. Since proanthocyanidins differ structurally according to the number of hydroxyl groups and oligomers contain a greater number of hydroxyl groups than polymers, oligomers probably would lead to stronger DPPH scavenging activity than polymers. In addition, the present results showed that oligomers had a more effective protective activity against protein oxidation induced by free radicals than polymers. Oxidative damage to a specific protein, especially at the active site, can induce a progressive loss of a particular biochemical function. Several types of ROSinduced protein modifications have been demonstrated, including the loss of sulfhydryl groups, formation of carbonyls, disulphide cross-links, nitrotyrosine, and glyoxidation and lipid peroxidation adducts, among others. Modified proteins and amino acids contribute to pathologies such as diabetes, aging, atherosclerosis, and neurodegenerative disease $(24,25)$. Therefore, we investigated the protective effect against protein oxidation induced by free radicals, using allophycocyanin as one of the phycobiliproteins of phycobilisomes, the accessory light-harvesting complexes in cyanobacteria and red algae, as a protein donor (26). The present study suggests that proanthocyanidins from persimmon peel exert radical scavenging activities and protective effects against oxidation induced by ROS. In particular, the activity of oligomers was more effective than that of polymers. The higher contents of hydroxyl group in oligomers than polymers would probably result in the stronger protective effect from protein oxidation by free radicals.

Oxidative stress is implicated as an important cause of degenerative diseases including diabetes (1-4), since hyperglycemia in diabetes increases oxidant production by multiple processes. Therefore, under the condition of diabetes, control of increased glucose flux plays an important role in diabetes progression and treatment. Moreover, inhibition of the digestive enzymes would delay the degradation of starch and oligosaccharides, which would in turn cause a decrease in the absorption of glucose and consequently inhibit the increase in postprandial blood glucose $(27,28)$. In particular, $\alpha$-amylase and $\alpha$-glucosidase participate in carbohydrate digestion, and are considered as key enzymes that can control postprandial hyperglycemia.

The antidiabetic potential of polymers and oligomers was evaluated through their inhibitory activities against $\alpha$-amylase and $\alpha$-glucosidase. In the results, polymers showed an inhibitory activity against $\alpha$-amylase, but oligomers exerted a low inhibitory activity against $\alpha$-amylase. $\alpha$-Amylase inhibitors could have a synergistic and potential therapeutic effect on postmeal blood glucose levels. The difference in inhibitory activity between polymers and oligomers may be caused by their structural differences. Horigome et al. (29) reported that the inhibitory activities of digestive enzymes such as $\alpha$-amylase, trypsin, and lipase were dependent on the polymerization degree of proanthocyanidin. In particular, the inhibitory activity of $\alpha$-amylase was positively and linearly related to the degree of polymerization. Therefore, polymers with a higher degree of polymerization than oligomers would exert a stronger activity against $\alpha$-amylase. On the other hand, the activity of $\alpha$-glucosidase is not related to the degree of polymerization, although further study also has to be supported. The present result showed both polymers and oligomers exerted effective inhibitory activities 
against $\alpha$-glucosidase activity; oligomers, particularly, showed a stronger inhibitory activity than polymers. $\alpha$ Glucosidase is involved in a variety of metabolic disorders and other diseases such as diabetes, viral attachment, and cancer progression (30-32). Because of their importance, glucosidase inhibitors can be useful tools for studying their action mechanisms and are also prospective therapeutic agents for some degenerative diseases. $\alpha$-Glucosidase inhibitors reduce glucose absorption by inhibiting disaccharide digestion, and thus delay the subsequent monosaccharide absorption. Several reports demonstrated that oral administration of specific $\alpha$-glucosidase inhibitors could effectively improve hyperglycemia as well as diabetic complications $(33,34)$. The present results support the role of oligomers as $\alpha$-glucosidase inhibitors, suggesting their promising potential against diabetes-related pathological conditions.

Under diabetes, the formation of AGE as glycated proteins results in the aggravation of diabetes and development of diabetic complications (35). In addition, AGE is themselves able to produce free radicals via complex biochemical mechanisms, and oxidative stress also accelerates AGE formation (36). Therefore, agents which can inhibit AGE formation and scavenge free radicals could be of great interest. In the present results, the oligomers and polymers inhibited AGE formation; in particular, oligomers showed a higher inhibitory effect than polymers under low concentration. This effect is probably associated with the structural characteristics of proanthocyanidins with hydroxyl and galloly groups. The glycosylation of proanthocyanidins with proteins increases their binding affinity in the presence of galloyl groups (10). The result in the reduction of AGE by treatment with polymers and oligomers suggests that they have a protective potential against diabetic complications induced by hyperglycemia as well as hyperglycemia itself.

The present study demonstrated that oligomers and polymers from proanthocyanidins of persimmon peel showed radical scavenging effects and protective activities against radical-induced protein damage. In addition, oligomers exerted an antidiabetic potential by inhibiting $\alpha$-glucosidase activity and AGE formation. On the other hand, polymers were suggested as effective $\alpha$-amylase inhibitors, while they showed a relatively weak inhibitory effect against $\alpha$-glucosidase. The difference between polymers and oligomers may be associated with their structures and activity sites. With consideration of their absorption in biological systems and functional properties, oligomers rather than polymers from proanthocyanidins of persimmon peel are expected as promising agents against diabetes. The functional properties support the utilization of persimmon peel, requiring further studies both in vivo and concerning related protective mechanisms.

\section{REFERENCES}

1) Lenaz G, Bovina C, D’Aurelio M, Fato R, Formiggini G, Genova ML, Giuliano G, Merlo Pich M, Paolucci U,
Parenti Castelli G, Ventura B. 2002. Role of mitochondria in oxidative stress and aging. Ann NY Acad Sci 959: 199-213.

2) Moreira PI, Siedlak SL, Aliev G, Zhu X, Cash AD, Smith MA, Perry G. 2005. Oxidative stress mechanisms and potential therapeutics in Alzheimer disease. J Neural Transm 112: 921-932.

3) Rahimi R, Nikfar S, Larijani B, Abdollahi M. 2005. A review on the role of antioxidants in the management of diabetes and its complications. Biomed Pharmacother 59: 365-373.

4) Valko M, Rhodes CJ, Moncol J, Izakovic M, Mazur M. 2006. Free radicals, metals and antioxidants in oxidative stress-induced cancer. Chem Biol Interact 160: 140.

5) Wolff SP, Dean RT. 1987. Glucose autoxidation and protein modification. The potential role of 'autoxidative glycosylation' in diabetes. Biochem J 245: 243-250.

6) Wolff SP, Jiang ZY, Hunt JV. 1991. Protein glycation and oxidative stress in diabetes mellitus and ageing. Free Radic Biol Med 10: 339-352.

7) Johansen JS, Harris AK, Rychly DJ, Ergul A. 2005. Oxidative stress and the use of antioxidants in diabetes: linking basic science to clinical practice. Cardiovasc Diabetol 4: 5-15.

8) Gorinstein S, Zemser M, Weisz M, Halevy S, Deutsch J, Tilis K, Feintuch D, Guerra N, Fishman M, Bartnikowska E. 1994. Fluorometric analysis of phenolics in persimmons. Biosci Biotechnol Biochem 58: 1087-1092.

9) Gorinstein S, Zachwieja Z, Folta M, Barton H, Piotrowicz J, Zemser M, Weisz M, Trakhtenberg S, Martin-Belloso O. 2001. Comparative contents of dietary fiber, total phenolics, and minerals in persimmons and apples. J Agric Food Chem 49: 952-957.

10) Santos-Buelga C, Scalbert A. 2000. Proanthocyanidins and tannin-like compounds-nature, occurrence, dietary intake and effects on nutrition and health. J Sci Food Agric 80: 1094-1117.

11) Ariga T. 2004. The antioxidative function, preventive action on disease and utilization of proanthocyanidins. Biofactors 21: 197-201.

12) Tanaka T, Takahashi R, Kouno I, Nonaka GI. 1994. Chemical evidence for the de-astringency (insolubilization of tannins) of persimmon fruit. J Chem Soc Perkin Trans I: 3013-3022.

13) Hatano T, Edamatsu R, Hiramatsu M, Mori A, Fujita Y, Yasuhara T, Yoshida T, Okuda T. 1989. Effects of the interaction of tannins with co-existing substances. VI. Effects of tannins and related polyphenols on superoxide anion radical, and on 1,1-diphenyl-2-picrylhydrazyl radical. Chem Pharm Bull 37: 2016-2021.

14) Courderot-Masuyer C, Dalloz F, Maupoil V, Rochette L. 1999. Antioxidant properties of aminoguanidine. Fundam Clin Pharmacol 13: 535-540.

15) Conforti F, Statti G, Loizzo MR, Sacchetti G, Poli F, Menichini F. 2005. In vitro antioxidant effect and inhibition of $\alpha$-amylase of two varieties of Amaranthus caudatus seeds. Biol Pharm Bull 28: 1098-1102.

16) Lee DS, Lee SH. 2001. Genistein, a soy isoflavone, is a potent $\alpha$-glucosidase inhibitor. FEBS Lett 501: 84-86.

17) Vinson JA, Howard III TB. 1996. Inhibition of protein glycation and advanced glycation end products by ascorbic acid and other vitamins and nutrients. J Nutr Biochem 7: 659-663.

18) Bagchi D, Bagchi M, Stohs SJ, Das DK, Ray SD, Kuszyn- 
ski CA, Joshi SS, Pruess HG. 2000. Free radicals and grape seed proanthocyanidin extract: importance in human health and disease prevention. Toxicology 148 : 187-197.

19) Urguiaga I, Leighton F. 2000. Plant polyphenol antioxidants and oxidative stress. Biol Res 33: 55-64.

20) Deprez S, Brezillon C, Rabot S, Philippe C, Mila I, Lapierre C, Scalbert A. 2000. Polymeric proanthocyanidins are catabolized by human colonic microflora into lowmolecular-weight phenolic acids. J Nutr 130: 27332738.

21) Xie DY, Dixon RA. 2005. Proanthocyanidin biosynthesis-still more questions than answers? Phytochemistry 66: $2127-2144$.

22) Scalbert A, Williamson G. 2000. Dietary intake and bioavailability of polyphenols. J Nutr 130: 2073S-2085S.

23) Deprez S, Mila I, Huneau JF, Tome D, Scalbert A. 2001. Transport of proanthocyanidin dimer, trimer, and polymer across monolayers of human intestinal epithelial Caco-2 cells. Antioxid Redox Signal 3: 957-967.

24) Dean RT, Fu S, Stocker R, Davies MJ. 1997. Biochemistry and pathology of radical-mediated protein oxidation. Biochem J 324: 1-18.

25) Sohal RS. 2002. Role of oxidative stress and protein oxidation in the aging process. Free Radic Biol Med 33: 3744.

26) Foguel D, Weber G. 1995. Pressure-induced dissociation and denaturation of allophycocyanin at subzero temperatures. J Biol Chem 270: 28759-28766.

27) Bischoff H. 1994. Pharmacology of $\alpha$-glucosidase inhibition. Eur J Clin Invest 24: 3-10.

28) Hirsh AJ, Yao SY, Young JD, Cheeseman CI. 1997. Inhibition of glucose absorption in the rat jejunum: a novel action of $\alpha$-D-glucosidase inhibitors. Gastroenterology 113: 205-211.

29) Horigome T, Kumar R, Okamoto K. 1988. Effects of condensed tannins prepared from leaves of fodder plants on digestive enzymes in vitro and in the intestine of rats. $\mathrm{Br}$ J Nutr 60: 275-285.

30) Dennis JW, Laferte S, Waghorne C, Breitman ML, Kerbel RS. 1987. $\beta$ 1-6 Branching of Asn-linked oligosaccharides is directly associated with metastasis. Science $\mathbf{2 3 6}$ : 582-585.

31) Gruters RA, Neefjes JJ, Tersmette M, de Goede RE, Tulp A, Huisman HG, Miedema F, Ploegh HL. 1987. Interference with HIV-induced syncytium formation and viral infectivity by inhibitors of trimming glucosidase. Nature 330: $74-77$.

32) Jenkins DJ, Taylor RH, Goff DV, Fielden H, Misiewicz JJ, Sarson DL, Bloom SR, Alberti KG. 1981. Scope and specificity of acarbose in slowing carbohydrate absorption in man. Diabetes 30: 951-954.

33) Rosenstock J, Raskin P. 1988. Hypertension in diabetes mellitus. Cardiol Clin 6: 547-560.

34) Koyama M, Wada R, Mizukami H, Sakuraba H, Odaka H, Ikeda H, Yagihashi S. 2000. Inhibition of progressive reduction of islet $\beta$-cell mass in spontaneously diabetic Goto-Kakizaki rats by $\alpha$-glucosidase inhibitor. Metabolism 49: 347-352.

35) Baynes JW, Thorpe SR. 1999. Role of oxidative stress in diabetic complications: a new perspective on an old paradigm. Diabetes 48: 1-9.

36) Bonnefont-Rousselot D, Bastard JP, Jaudon MC, Delattre J. 2000. Consequences of the diabetic status on the oxidant/antioxidant balance. Diabetes Metab 26: 163-176. 